In this connection I find that in four cases of vitreous hemorrhage Paton ${ }^{24}$ and Paramore ${ }^{24}$ found diminished clotting time, and Wright suggested that in these instances the hemorrhage might be due to thrombosis taking place in a small vein. Clearly the part plared in this disease by abnormal coagulation of the blood is purely a matter of speculation at the present time and remains for future investigation to solve.

Professor Axenfeld has kindly written me that the progress of his case is still satisfactory. There have been no fresh hemorrhages and the vision two months ago was $6 / 12$. I understand that he has had the carotid tied in a second case, but that it is too early yet to judge of the result. A detailed history of his first case may be found in the dissertation of Fraillein Bieber, ${ }^{25}$ and from ler paper I take this occasion to quote Siegrist's figures of 6 per cent. mortality in 997 cases of carotid ligation gathered from the literature. This writer (Siegrist) is of the opinion that if the patient's condition be goot and if compression of the artery be carried out methodically before the operation, then ligation may be perforincd without serious danger to the patient.

fror tile discussion, see the departarext of Sectro. DisCLSSIONS IN TIIS ISSEE.]

\section{METASTATJO CONJUNCTIVITIS IN GONORRHEA.*}

\section{JAMES J. CARROLL, M.D.} BALTIMORE.

Although gonorrhea was known to the ancients and ophthalmia neonatorum to the early Greeks and Arabians, ${ }^{1}$ the true relation of the parent disease to its affiliated inflammations of the eye was still very imperfectly understood even at the beginning of the ejghteenth century. While many of the primitive physicjans appear to have fully recognized the ophthalmia of infants, it was not until $1750^{2}$ that it was believed to depend on the vaginal discharge of the mother. Before this the theories as to its origin were rather vague, the old physicians of India, for example, ascribing it to the bad character of the mother's milk. In later ycars the ophthalmia of adults was thought by some to be due to gonorrheal virus seeking another outlet in consequence of suppression of the urethral discharge. Acting on this view J üngken ${ }^{3}$ recommended, in his text-book, the reestablishment of the flow from the urethra as the proper treatment for the ocular disease.

Without citing all the views and opinions in regard to gonorrheal affections of the eye which were in vogue before 1700, it will suffice to state that nearly all of them contained a belief in an internal or indirect route by which the venereal virus reached the eye in contradistinction to a direct or external route. This endogenous conception of the origin of gonorrheal affections of the eye prevailed until the time of Astruc, ${ }^{4}$ who, in 1736 , published the report of a case of purulent conjunctivitis which he attributed to direct infection, by the hands,

\footnotetext{
24. Lancet, 1905, 1249.

24. Lancet, $1905,1249$.
25. Inaug. Diss. Frelburg, Berlln, 1906.

25. Inaug. Diss. Freiburg, Berlin, 1906 . cal Association at the Fifty-eighth Annual Session, held at At lantlc City, June, 1907 .

1. IIirschberg (J) : Geschichte der Augenhcilk., 1899, xil, 297 of Graefe-Saemisch Handbuch der gesamten Augenheilkunde, 2d Fd.

2. Guellmalz: Ref, in Graefe-Saemisch Handbuch, etc., 2d Ed., $\mathbf{0}$, chap. $1 \nabla$, p. 238 .

3. Jiinsken: Dile Lehre von den Augenkrankheiten, Berlin, 1832 p. 252 .

4. Astruc: De morbis Veneris, 1736,102 . Lutetiæ Inusiorum.
}

from the uretlin: This new thery made very slow progress. Although it was greatly strengthened in the beginning of the ninetecnth century by the support of Jaeger, by the publication of Allan ${ }^{5}$ and the lectures of Mr. Abernethy at St. Bartholomew's Hospital, it did not supersede the old belief entirely until the experiments of Piringer ${ }^{\tau}$ firmly established the direct causative relationship betwcen the infecting matcrial of the urethra and the inflammation of the conjunctiva.

After the convincing proofs of this investigator were known, the pendulum soon swung to the extreme, and it was not long before Ruete ${ }^{s}$ and Arlt $^{3}$ maintained that all gonorrheal affections of the conjunctiva were the result of direct inoculation. While this was the prevailing belief, Fournier, ${ }^{10}$ in 1866 , described a type of conjunctivitis, occurring in a gonorrheic with inflamed joints, which he regarded as metastatic. In 1881, Haab ${ }^{\mathbf{1 1}}$ reported a case of bilateral conjunctivitis, which he saw in a patient with gonorrhea and which he thought was not the to direct infection on account of the absence of gonococci in the conjunctival secretion. In 1885, Haltenhof ${ }^{12}$ reported five cases of gonorrheal conjunctivitis without inoculation. In the following decade and a half appoared similar publications by Rückert, ${ }^{13}$ Liebrecht, ${ }^{14}$ Vanderstracten, ${ }^{15}$ Parinaud, ${ }^{16}$ Morax, ${ }^{17}$ Lipski, ${ }^{18}$ Nobl. ${ }^{19}$ Giclen, ${ }^{20}$ Becker, ${ }^{21}$ Lichitenstern, ${ }^{22}$ Fage, ${ }^{23}$ Morton" ${ }^{27}$ and others. In 1899 , the subject was brought before the Ninth International Congress of Ophthalmology by Van Moll, ${ }^{25}$ of Rotterdam. who reported six cases of his own observation. Kurka, ${ }^{26}$ in 1902 , published an account of twentr-two cases, two of which were seen by him in Professor Fuchs' clinic in Vienna and the others were taken from the literature. Later cases have been reported by Lesser, ${ }^{27}$ Apetz, ${ }^{28}$ Thorner, ${ }^{29}$ Sym, ${ }^{30}$ Paul, ${ }^{31}$ Burnett 32 and others.

5. Allan: System of Pathological and Operative Surgery, Edinburgh, 1810 , i, 153

6. Abernethy: Lancet, London, 1825 , p. 5 .

7. I'iringer: Die Blennorrhoe am Menschenauge. Gratz, 1841

8. Ruete: Lehrbuch der Ophthalmologie. Braunschweig, 1845

9. ArIt: Die Krankheiten des Anges, Prag, 3d İd, 1854, 1, 45

et Chir. pract., réd. par

11. Ilaab: Cor-Bi. f. Schweiz. Aerzte, 18,1, No. 4, 105.

12. Taltenhof: Ueber Conjunctivitis gonorrboica ohne inoculation. Archiv f. Augenheilk, von Knapp u Schweigger, 1885, xix 13.120.

13. Rilckert: Ueber Iritis, Confunctivitis, Pollarthritis gon. Klin. Monatsb. f. Augenh., 1886, xxiv, 339-358,

14. Llebrecht: Kasulstiche Beiträge aus Prof. Schöler'schen ugenklinik, Klin. Monatsb. f. Angenh., 1891, xxix, 176-17?

15. Vanderstraeten: Des affections oculaires de nature blennor16 gue. Arch med. belges, 1891, xi, 300 .

16. Parinaud : Congr. d'Opht., Paris, 1891.

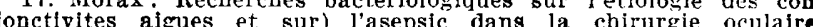
These de Paris, 1894.

18. Lipski: Des complications

18rhagie, These de Paris, 1895 . Wiener med. Ueber seltenere Komp

lener med. Zeltung, 1895, No. 33 . Affectionen der Urethra. Diss. Bonn.

21. Iecker: Die metastatische gonorrholsche Augenbindehant Erkrankung. Jabresb f. Natır- und Heilkunde, Dresden, 1897 -ns. 22. Lichtenstera: Zwel Falle ron gonorrhoischer Allgemeininfection. Prager med. iFochschr., 1898, No. 43.

23. Fare: Conjonctivite blennorilagique metastatlque, Teeretl donit.. Anili, 1900

24. Morton: Relation of Certaln Catarrhal and Suppurative Infammations of the Confunctiva to Urethritis and Arthritis onhthalmic Record, June, 1900.

25. Van Moll : Giebt et eine metastatische Conjunctivitis? I Internat. Congr. of Ophthal., Utrecht, 1890

26. Kurka (A.) : Ueber metastatische Bindehautentzündung bel Gonorrhoe. Wien. klin. Wochschr.. 1002, No. 40

2.7. Lesser: Coniunctivitis duplex rheumatica nach Gonorrboe Münch. med. Nochschr., 1902. No. 29.

28. Apctz (WV): Ueber gonorrhoisch-metastatische Entzinduns am Auce Frwachsener. Mïnch. med. Wochschr.. Aus. 4, 1903. 20. Thorner: Ueber metastatische Confunctivitis gonorrhoica Charitê Ann., Berlin, 1904, xxvili, 340-347.

30. Sym (TV. G.) : Metastatic Gonorrheal Ophthalmia. Edinburgh Med. Jour., 1904, 126-129, vol. xvi.

31. Paul: Netastatische-gonor rholsche Augenaffektion. Berl. klin. Wochschr., 1905 . No.9.

32. Rurnett (S. M.) : Inflammation of the Fre Due to the Toxin of the Gonococcus. 'Tine Jot'rial A. M. A., 1005, xlv, 1926-1928. 
In revicwing the text-books, I find that few gire any space to metastatic gonorrheal conjunctivitis. 'The silence of many authors on this subject may be due to the fact that the field of ophthalmology has become so vast that it is almost impossible to cover it entirely without omitting one of the less frequent diseases. Of thirtyfour books on the eye which have appeared in English, either as the original or as a translation, during the past twolve years, the disease is given in seven, being mentioned in two (Ramsey, Swanzy and Werner) and described in five (Fuchs, Schmidt-Rimpler, Lawson, Norris \& Oliver's System, de Schweinitz). Many textbooks, too, on genitourinary diseases fail to mention it, though Taylor, Fuller, Keys, White and Martin have a description.

One naturally hesitates to report as few as two cases, even though they furnish the main reason for this paper, which is to give the ophthalmologists of the Association an opportunity to express their views on a subject which, so far as I can learn, has never before been formally presented to the Section. A free discussion may do much to make this form of conjunctivitis better known, may help to determine the frequency of this disease in our country, may be the means of dispelling doubts which, I fear, still remain in the minds of some as to its existenee, and may possibly suggest to some one a line of work for original investigation.

CAsE 1.--T. C., white, aged 35, was in the second week of a first attack of gonorrhea, when his right eye became inflamed.

Examination.--Patient, with no history of rheumatism, came under mv observation for the first time Jan. 19, 1905, at St. Joseph's Hospital, Baltimore, his ocular trouble having existed about ten days or two weeks. There was at that time photophobia, lachrymation, some soreness about the eye, but no decided pain, no swelling of the lị̂s, pronounced injection of the conjunctiva of the eyeball with slight swelling, the episcleral ressels being well filled. There was a moderate amount of mucopurulent secretion; cornea, iris and deeper parts were in good condition; vision was not affected; the left eye was normal.

Subservent History.-The right ankle had begun to swell and to give pain twenty-four hours previously, and two days later the patient suffered severely from pain in the region of the sacrum, which was in turn followed by pain and swelling of the right knee, and pain but no swelling of the right wrist. The inflammation of the right conjunctiva subsided under local treatment in about eight days. A day or so after the patient was first seen a Buller's shield was placed over the left eye to prevent any possible infection from the urethra or from the right eye. Under this protection the eye began to show signs of conjunctival inflammation three weeks after the other became diseased. The character of the conjunctivitis on the left sicle was identical with that on the right, but its course was shorter, due, probably, to the influence of earlier treatment. Pain and swelling of the left ankle and pain in the left wrist followed quickly on the onset of conjunctivitis on the left side. Whon this seemed almost well the patient was taken with pain in the left eye, accompanied by marked increase of redness of the ereball, ciliary injection, and hyperemia of the iris. The pain soon became severe and the aqueous muddy; the pupil dilated imperfectly under atropin. showing three small posterior synechia. The anterior chimber became one-quarter filled with blood; the pupil was obscured by dull grayish deposit and the fundus was invisible. The eyeball was very inder to slight pressure and vision was reduced to counting fincrers at four feet. The iritis lasted five weeks. The exullates slowly became absorbed and vision returned to $20 / 20$. At one time during the course. of the iritis on the left side the right eve became painful, showing some ciliary injection and disccloration of the iris. Atropin was used freely and no further derelopments were noted.

Bacteriologic Examination-Coverslips alone were used. Pus from the urethra showed gonocneci. Secretion from the con- junctival sac of each eye was repeatedly examined tut alway. with negative results.

The case at first presented a complex of symptoms with which, I confess, I was not altogether familiar. It seemed perfectly clear that the condition was not gonorrheal ophthalmia or acute blennorrhea, and its resemblance to acute catarrhal conjunctivitis was not borne out by other clinical phenomena present, as gonorrhea and arthritis. The diagnosis of metastatic conjunctivitis was based on the following points: (1) the existence of a urcthritis with gonococci, (2) the character of the conjunctivitis, (3) the absence of gonococci in the conjunctival secretion, (4) the presence of polyarthritis.

CASE 2.-J. H., white, aged 39 , was referred to me by his family physician, Dr. W. T. Riley, March 5, 1907. The patient, with no history of rheumatism, was in the fourth week of a first attack of gonorrhea, involving both anterior and posterior portions of the urethra and producing prostatic enlargement and swelling of the seminal vesicles.

IIistory. - The trouble started March 1 , in both eyes simultancously, with mild photophobia, lachrymation, redness, and slight secretion. Accompanying the onset of the ocular symptoms were frontal headache, vertigo, coated tongue, loss of appctite, clilly sensations, temperature 100 F., occasional sweating, pains in the lumbar region, in the right leg above the internal malleolus and in the larger phalangeal joint of the middle finger of the right hand. The eyes soon became worse, the lids being stuck together in the morning and the eyeballs more "bloodshot."

Examination.-The patient came under my observation on the fourth day, the condition then being about as follows: Marked injection of the conjunctiva, limited almost entirely to the fornix and globe, some swelling of the conjunctiva, particularly in the region of the limbus; several small conjunctival hemorrhages in each eye; episcleral vessels congested; moderate amount of mucopurulent secretion; no swelling of the lids; cornea and iris good; pupils small, though responding well to Iight; vision $20 / 30$ in each eye, the slight impairment being lue to myopic astigmatism.

Subsequent History.-Next day the eyes were worse, chemosis of the conjunctiva being rather prominent. The iris too showed for the first time unmistakable signs of inflam. mation. The pupils failed to react to light or fully to atropin, and vision sank rapidly to counting fingers at three feet. At the end of the first week the swelling of the conjunctiva was much less and there was hardly enough secretion in the conjunctival sac to get a smear for coverslip examination. The iritis, on the other hand, was rather more active; the aqueous was somewhat cloudy; there was a slight exudate in the pupillary area; the pupils were small and irregular, showing four or five posterior synechiæ in ench eye, no precipitates were discernible on the posterior wall of either cornea; fundi were invisible. Pain in middle finger and leg on the right side was about the same. The patient about this time began to complain of pain in the left ankle, which was not severe and not accompanied by any swelling. At the end of the sccond week the iritis was still prominent. Fair dilatation of the pupils had been secured by the frequent use of atropin; the ereballs were somewhat tender on palpation; there was no pain in the eyes, but dull frontal headache was occasionally folt. At the end of the third week there was improvement in the urethritis, in the inflammation of the eyes, and in the general condition of the patient, although pain was still present in the lumbar region, made worse by moving in bed. During the fourth week the eres made little or no advance toward recovery. In the following week improvement was rapid and by the middle of the sixth week the eyes were practically free from inflammation and vision was normal with the assistance of minus cylinders to correct a little astigmatism.

Bacteriologic Examination.-This was made by Dr. E. H. Hayward, pathologist of St. Joseph's Hospital. Smears, taken when paticit was recovel into the hospital on the fifth day of 
his conjunctivitis, showed no gonococci in the secretion from the eye, but numerous gonococci in the pus from the urethra. Coverslips were examined twice a day as long as there was any secretion in the conjunctival sac, and always with negative results. Cultures from the secretion of the cye were made on human blood serum, blood agar, hydrocele agar, and all were negative. CuIture on Loeffler's blood serum showed a single white crlony of staphylococci. Culture from patient's blood on human blood serum was negative.

Though arthritis was not conspicuous as in the first case, the diagnosis in the second instance was based on the coexistence of gonorrheal urethritis, the type of bilateral conjunctivitis, the absence of gonococci in the conjunctival secretion, the iritis which appeared on the fifth day, and the slight but appreciable systemic disturbance.

In reviewing the literature on the subject I find that this form of conjunctivitis has been described under various names, as metastatic gonorrheal conjunctivitis, metastatic gonorrheal ophthalmia, gonorrheal conjunctivitis without inoculation, serovascular conjunctivitis, rheumatic gonorrheal ophthalmia, arthritis catarrhorheumatic ophthalmia, etc. In order to avoid confusion, it seems wise to adopt the title given in the second edition of the Graefe-Saemisch Handbuch, namely, metastatic conjunctivitis in gonorrhea.

Although described under so many different names, the disease has been represented with the same essential characteristics. The constancy with which these clinical phenomena appear together, and the number of such occurrences, preclude the possibility of mere coincidence. A study of the reported cases, as well as of the two which came under my observation, furnishes sufficient data for a rough description of the main clinical features of the disease. The primary infection being gonococcal, the disease starts out with an ordinary purulent urethritis. Usually rather early in the course of the gonorrhea, but at times during a second or subsequent attack, a conjunctivitis appears. The inflammation involves chiefly the conjunctiva of the fornix and eyeball, giving rise to marked redness and swelling and at times chemosis. Often the episcleral vessels are engorged, showing the characteristic pinkish or violet color. The secretion is mucoid, or mucopurulent. It is usually moderate in amount and contains no gonococci. The subjective symptoms are photophobia, lachrymation, slight soreness of the eye, and occasionally pain. Vision is not affected if the deeper ocular structures are not implicated. The conjunctivitis involves both eyes, either at the same time or in rapid succession, and ends in the restoration of the conjunctiva to the normal. It usually comes on before the joints are attacked, although this order may be reversed. The inflammation is occasionally limited to the conjunctiva, but it is more often accompanied or followed by iritis or iridocyclitis. When inflammation of the uveal tract occurs, it is usually of the serous or plastic variety. Ieratitis is rare, varying in degree from a small area of infiltration to ulceration. Retina and optic nerve are very infrequently involved. In consequence of these complications vision may be very much reduced, but, barring corneal destruction, it returns as the intraocular exudates are absorbed. Though arthritis is not a necessary factor of the diseased process, it is almost always present. It generally occurs in more than one joint, the larger ones being more often attacked than the smaller.

An interesting feature of the disease is its tendency to recur. A new attack of conjunctivitis, followed by pain and swelling of the joints, may appear after a fresh outbreak of gonorrhea and be equally as severe as the first.
In several instances the cornea and iris have become involved in the recurring attack after having entirely escaped in the initial one. Furthermore, an increase in the urethral discharge is often the forerunner of an exacerbation of both conjunctival and joint affection. In a case reported by Rückert there were three occurrences of urethritis, two of which were followed by conjunctivitis, one by iritis. In the case of Apetz there were two recurrences and two exacerbations, in all of which the conjunctiva was correspondingly involved. A single recurrence is more frequently met.

It may not always be possible to distinguish this disease, though in the majority of cases a diagnosis offers very little difficulty. The diseases which come into question are acute blennorrhea or gonorrheal ophthalmia of the adult and actue catarrhal conjunctivitis. The clinical picture of a typical case of the former is sufficiently characteristic to leave no doubt as to diagnosis, the tensely swollen lids, the greatly infiltrated conjunctiva, the profuse flow of pus containing gonococei being in marked contrast to the bilateral affection of metastatic origin with soft Iids, relatively smooth conjunctiva of the lid and moderate mucopurulent seeretion containing no gonococci. The diagnosis, however, must be made with care on account of the possibility of the case in question being one of mild gonorrheal ophthalmia, in which the virulence of the urethral infection was greatly weakened before the eye was inoculated. In such, an early bacteriologic examination of the conjunctival secretion will usually reveal the gonococcus, thus establishing the exogenous character of the inflammation. If, however, no gonococci are found, the existence of a metastatic arthritis or iritis will point to an endogenous infection of the conjunctiva.

From an acute catarrhal conjunctivitis the differentiation is not so easy if we regard the ocular condition alone. However, the Iocalization of the inflainmatory process, more in the conjunctiva of the fornix and eyeball than on the lid, and the presence of a deep cpiscleral injection, will strongly suggest metastatic conjunctivitis. The coexistence of gonorrhea will be additional evidence, and should an arthritis be present the diagnosis will no longer be in doubt, because metastases never exist in genuine catarrhal conjunctivitis. Even without metastatic joint inflammation the diagnosis may still be made by finding gonococci in the circulating blood.

Can simple iritis or iridocyclitis be mistaken for metastatic conjunctivitis? The congestion of the eye, if taken by itself, may not always be sufficiently characteristic to enable one to distinguish between the two, but if the patient is seen early, swelling and chemosis of the conjunctiva and mucopurulent secretion will exclucle simple iritis with certainty. If, however, the patient is seen late, when the conjunctival symptoms proper have become less marked or are obscured by the involvement of the uveal tract. it may be no Ionger possible to tell from ocular appearances alone whether the initial inflammation was in the conjunctiva or in the iris. It goes without saying that in those cases of metastatic conjunctivitis in which no part of the uveal tract becomes involved iritis does not enter into the question of differential diagnosis.

All reported cases of metastatic gonorrheal conjunctivitis have occurred in men. Whether any reason exists for this in the anatomy of the male urethra and its adjacent organs it is difficult to say. Many authorities claim that srstemic infection occurs more often through 
the prostatic portion of the urethira, wilile, according to Fuller, the seminal vesicles constitute the route freguently taken by the gonococcus or its poison in entering the general circulation.

The old belief of gonorrhea being purely a local disease has been made untenable by modern investigators, who liave found gonococci in the circulating blood (Wrertheim), in the fluid of arthritic joints, and in the heart (Thayer). The prevailing and well-proven belief is that, in addition to the local urethritis, gonorrhea may produce systemic lesions by the transportation of infec, tious material through the lymphatic or blood channels from the original seat of disease to distant parts of the body. In full accord with this are the clinical reports of gonorrheal complications which appear in the literature. Besides arthritis, we have well-authenticated cases of gonorrheal pericarditis, endocarditis, myocarditis, pleuritis, nephritis, phlebitis, myositis, subcutaneous abscess, general septicemia, diseases of the peripheral and central nervous system, and Iesions of the skin. With this advance in knowledge before us regarding gonorrhea in its relation to the general system, it may not be amiss to ask ourselves if we, as ophthalmologists, should not modify our views of gonorrhea in its relation to the eye. Such a suggestion seems all the more timely, as many authors of text-books on ophthalmology give iritis alone as a possible metastatic complication of gonorrhea. Since Mackenzie first recognized gonorrheal iritis, reliable publications have appeared from time to time of cases of metastatic dacryoadenitis, ${ }^{3: 3,34}$ conjunctivitis, tenonitis, ${ }^{35}$ keratitis, ${ }^{36,37}$ iridochorioiditis, ${ }^{38,39}$ retinitis, ${ }^{\mathbf{4 0}, 41,42}$ neuroretinitis, ${ }^{\mathbf{4 3}}$ optic neuritis, ${ }^{\mathbf{4}}$ and panophthalmitis, ${ }^{45}$ all depending primarily on gonorrheal infection. In point of frequency, iritis is the most common, occurring, according to De Lapersonne, once or twice in 7,000 eye cases and conjunctivitis next. Kurka saw 2 cases of this in 20,000 patients frequenting Professor Fuchs' clinic in one year.

The work of investigators in determining the infecting material which brings about this metastatic conjunctivitis, and in establishing its relationship to the underlying disease has not been rewarded with uniform results. As a consequence three theories have arisen:

1. Some authorities maintain that the inflammation is due to the presence of the gonococcus in the conjunctival sac, the organisms being carried thither by the blood vessels. This is supported by the bacteriologic

33. Cause (F.): Metastatische Tränendrüsenentzündung bef Gonorrhoe. Ztschr. f. Augenh., 1904, xi, 399.

34. Panas: Dacryoadénite, tritts, et conjunctivite sero-vasculaire d'origine blennorrhagique. Jour. des Prat, Feb. 21, 1894.

35. Puech : Un cas de ténonite. Clin. ophth., January, 1895.

36. Martin: Recherches anatomo-patbologiques sur les inflammations métastatiques a la suite de la gonorrhée. Génève Diss. Ref. in Arch. f. Augenhell., xiv, 117.

37 . Burchardt: Entztindung der Iris, der Hornhaut, der Sehuervenscheibe und der Netzhaut infolge von Gonorrhoe. Charité Annalen, 1897,345 .

38. Bull (C. S.) : Systemic and Constitutional Character of Gonorrhea, illustrated by five cases of iridochoriolditis. Med. Record, 1002 , 1xii, No. 25 .

39. Galezowski: Des irłdo-chorioidites gonococciques. Progres Med., January, 1905

40. Burchardt: Entzündung der Iris, des Strahlenkörpers des linken Auges, Netzhautentziundung beider Augen, und mehrfache Gelenksentzündungen nach Gonorrhoe, Charité Annalen, 1894, 246.

41. Galezowskl: Sur les altérations vasculatres de la rétine dans l'infection olennorrhagique. Ann. d'Oculist, 1300, 1, 301.

42. Hilbert: Retinitis infolge ron gonorrhoischer Infektion. Ztschr. f. prakt. Aerzte, vif.

43. Highet: Case of Neuro-retinitis. Abst. in Med. Bull, Phila, April, 1 s96.

44. I'ants: Nevrite optique d'origine blennorrhagigue. Presse Méd., 1S95. 64.

45. Galezowsli : Irido-chorioldite avec nevrite optique et panophtalmie dans une meningite cérebro-spinale gonococcique. Rec. d'Opht., l'aris, 1903 , $x \times v .309$. examinations of Lipski, Morax, and Van Moll, who found the gonococcus in the conjunctival secretion. The experience of these three observers is almost unique, as the great majority have failed to find the specific organism. In a review of 26 bacteriologic examinations of 40 reported cases $I$. find that 22 showed no gonococci in the conjunctival secretion, 3 gave the organism in small numbers, and 1 examination was doubtiul. Adding my 2 cases makes a total of 28 examinations, 24 being negative, 3 positive and 1 doubtful. Kurka, thinking the gonococci might be under the epithelium, excised a piece of conjunctiva from one of his patients and examined it microscopically, but was unable to detect the organism. The advocates of this theory bring to its support the investigations of Kämmerer, Petrone, von Lindemann, Höck and many others who have found gonococci in the fluid of arthritic joints, arguing by analogy that the same infection occurs in the conjunctiva. While the bacteriologic examinations in metastatic conjunctivitis are not conclusive, it seems probable, in view of the inability of observers to find the gonococcus in the conjunctival secretion, that some other infective agent must be the chief one in this inflammation.

2. The second theory is that the conjunctivitis is the result of mixed or secondary infection; that the gonococcus does not play the important rôle, but rather prepares the soil for another organism as the staphylococcus, the streptococcus, or the pneumococcus. Van Moll found the first in the conjunctival secretion of five out of his six cases, and, inasmuch as the staphylococcus has bcen frequently found in the fluid of gonorrheal joints, he concluded that the conjunctivitis was probably a mixed infection in which the staphylococcus was the chief agent. To this it may be objected that staphylococci are often found in the normal human conjunctiva and that, as Axenfeld has said, they show themselves in the conjunctival sac at the slightest irritation, even when they are not the exciting catuse. Many authorities who adhere to the theory of mixed infection base their belief largely on those experiments made on gonorrheal joints in which the gonococcus was not found, but in which the staphylococcus was the organism in evidence. Conclusions, however, from joint examinations must be drawn with care, because with the common method of aspirating joints the gonococcus, if imbedded in the synovial membrane or present in the periarticular tissues, may easily go undetected. From conversations with laboratory workers I learn that it is their experience that with modern technic and careful examination of gonorrheal metastases the gonococcus is found more frequently in pure culture than formerly, and cases of so-called mixcd infection are becoming less frequent.

3. The third and perhaps the most tenable theory founded on present knowledge is that this type of metastatic conjunctivitis is not directly and esscntially an jnfection by the gonococcus itself, but is the result of a poisonous product of this organism acting on the cellular elements of the conjunctiva. This possibility was suggested by Axenfeld in discussing Van Moll's paper at Utrecht in 1899. The majority of writers since then are more inclined to this view than any other. It seems, too, to be well supported by the experiments of Wasscr. mann, ${ }^{46}$ Nicolaysen, ${ }^{47}$ Laitinen, ${ }^{48}$ Grosz and Kraus, ${ }^{49}$

46. Wassermann: Ueber Gonococcuskulture und Gonococcengift. 46. Wassermann: Ueber Gonococ
Berl. klin. Wochschr., 1897 , No. 32 .

47. Nicolaysen : Zur Pathogenitit und Giftigkeit des Gonococcus. Centrbl. f. Bact., 1897, xxil, p. 305.

48. Laltinen: Beitrage zur Biolo
Kenntnis der Bact., 1898, xxiii, 874. 49. Grosz und Krars: Bacterinlo

Untersuchuncen uber den Gonococcus. Archiv. f. Derm. und syph., 1898, xlv, 329 . 
Christmas, ${ }^{50}$ Morkx and Elmassian, ${ }^{51}$ and Randolph, ${ }^{52}$ These investigatos's have demonstrated that the gonococcus generates a specific active poison, the gonococcustoxin, which is contained in the body of the organism. All of them agree that the bodies of gonococci possess this toxic material, but all do not hold that one is artificinily separable from the other. Wassermann, Nicolay. son and Laitinen maintain that the poison is confined to the body of the organism, while Christmas, Morax and Elmassian and Randolph believe that it may be, at least in part, dissolved in the liquid of the culture medium. While the toxin has not been chemically defined as yet, it has been proved by biologic test to possess propertics separate and listinct from those of the gonococeus. The latter is destroyed by a temperature of 40 (. (Wossidlo), while its toxin is destroyed by a much higher temperature, according to Christmas 80 C., according to Morax and Elmassian $115 \mathrm{C}$. It is very much more difficult to preserve artificially the activity of the gonococcus than that of its toxin. While it is impossible to obtain an inflammation with proliferation of the gonococeus on the animal conjunctiva, whatever the mole of inoculation, it is quite possible, according to Morax and Elmassian, to obtain an analogous condition by instilling the toxin into the conjunctival sac of the ribbit. It has also been shown that intraperitoneal as well as subcutaneous injections of the toxin have produced death in animals, chictly guinea-pigs and white mice, and a solution of this poison has causec urethritis. lifiering from the genuine gronorrliea only by the absence of ronoesci.

Without giving in detail the work of the various investigators of this subject, I wish to refer to the experiments of Morax and Elmassian, which were given to the Utrecht Congress of Ophthalmology and with which all members of this Section are doubtless familiar. It will be recalled that these Frenchmen experimented with the live as well as the dearl cultures of the gonococcus; that they instilled into the conjunctival sac of rabbits and man an emulsion of dead gonococci and the filtercd cultures of these organisms and produced an inflammatory conjunctivitis both in the rabbit and in man. That this reaction was not a mere mechanical - effect was proved by control experiments. The possibility of the gonococcus having anything to do with it was excluded by boiling the medium. It scemed perfectly clear to the minds of the investigators that this artificially produced conjunctivitis was due directly to the action of the toxic substance which they dissolved from the bodics of gonococci.

The results of Morax and Elmassian might seem at first sight to be contradicted by the more recent work of Randolyh in the Johns Hoplins laboratory. The latter experimented with filtrates of the gonococeus on rabbits and found that simple instillation into the conjunctival sac produced reaction in only one instance. In the animals which showed no conjunctival reaction, the instillations were continued from 15 minutes to 3 hours, while those of Morax and Elmassian were kept up from 2 to 7 lours. the majority being from 5 to 7 hours. It may be that the difference in duration of instillation may account in part for the difference in results. Randolph,

50. Curistmas: Contribution a létude du gonococcus et de sa toxine. Ann. de l'Inst. l'asteur, 1900.

51. Morax and Elmassian: Du rôle des toxines dans la prođuc tion des inflammations do la conjonctive. ix congrès Internat. Oihthajnologie, Utrecht, 1s09, Angust.

i2. landolpta :The loole of the roxins in Inflammations of the

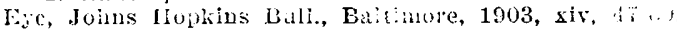

however, produced a conjunctivitis in every case in which he injected the filtrate into the conjunctiva. By introducing the toxin under the epithelium he facilitated absorption and produced a local reaction more quickly than could be obtained by continuous instillation.

Although the investigators who have been working along the line of the present subject have brought to light most valuable information, they have not produced uniform results. Reasons for this are not hard to find: 61) The technic of the investigations is very difficult; (2) most animals are not affected by the gonococcus, though they seem to be susceptible to its toxin; (3) the nature of the gonococcus toxin is still very much in doubt; (4) gonorrheal metastases of the ejeball lend themsolves badly to experimentation; (5) metastatic conjunctivitis beirg rare, opportunities for studying the disease seldom present themselves.

To me the study of this subject has suggested that perhaps better data might be furnished if the bacteriologic cxamination in each case of metastatic gonorrheal conjunctivitis were made early and included not only the conjunctival secretion, but also the blood, and the effusion of the joints if arthritis be present.

In conclusion, it may be suggested as a fair hypothesis in the light of our present knowledge that while it is possible, as maintained by Morax thirteen ycars ago, for a few cases of metastatic conjunctivitis to be caused by the gonocosens in the conjunctival sac, it is probable that the essential agent in the great majority of cases is not the gonococcus acting on the ocular mucosa, but a specific poisonous product of this organism called its toxin.

[Fer tile Discussion, SEe TIIE department of Section Discussions IN THIS ISSCE.]

\section{TIIE TREATMENT OF. IAACHRYMAL OBSTRUCTION.*}

MARK D. STEVENSON, M.D.

AKroN, ollio.

Before this Section it is not necessary to discuss the treatment of all the various obstructive causes of epiphora. Those cases due to psychic or reflex causes, to refractive crrors or in which hypersecretion is due to other non-obstructive causes will not be considerei. The treatment of those portions of the tear clrainage apparatus above the lachrymal sac, being well understood, will receive but little attention. Howerer, further consideration of the treatment of pathologic enculitions of the lachrymal sac and nasal duct, especially if it lears to free discussion, seems timely, since the diverse methods now employed indicate tliat it is not well understond. The necessity of treating abnormal conditions in the nose will be emphasized, since they are very important in the etiolory of these affections.

For purposes of treatment, I divide the tear drainage apparatus into three parts. The upper portion inciudes tle puncta and canaliculi. The treatment of this upper part has been much discussed and is fairly satisfactory. The lower portion, an examination of which should never be neglected, and the treatment of which is often

* Read in the Section on Ophthamolnes of the American Mecli. eal Association at the Fifty-cishth Aisual Sessiun, heid at Atlatuc cits, June, Ison. 